\title{
Eccentric superior mesenteric artery calcification in a haemodialysis patient
}

\author{
Orhan Ozbek, ${ }^{1}$ Yalcin Solak, ${ }^{2}$ Abduzhappar Gaipov, ${ }^{2}$ Suleyman Turk ${ }^{2}$ \\ ${ }^{1}$ Department of Radiology, Meram School of Medicine, Konya University, Meram, Konya, Turkey \\ ${ }^{2}$ Division of Nephrology, Department of Internal Medicine, Meram School of Medicine, Konya University, Meram, Konya, Turkey
}

Correspondence to Dr Abduzhappar Gaipov, abduzhappar@gmail.com

\section{DESCRIPTION}

A 43-year-old male patient who was undergoing maintenance haemodialysis for 11 years underwent abdominal CT scan due to a suspected malignancy. He had type-2 diabetes mellitus for 15 years. Abdominal CT revealed that there was diffuse atherosclerotic calcification in superior mesenteric artery (SMA) and its branches (figures 1 and 2). No radiological findings of ischaemia were evident on CT images. Symptoms of chronic mesenteric ischaemia (CMI) were not present either. The patient denied any abdominal pain after meals or during the dialysis session.

Metastatic vascular calcification is one of the most dreaded complications of long-term haemodialysis treatment. ${ }^{1}$ It is most commonly seen at branch points (origin points of the branching arteries) and at particular

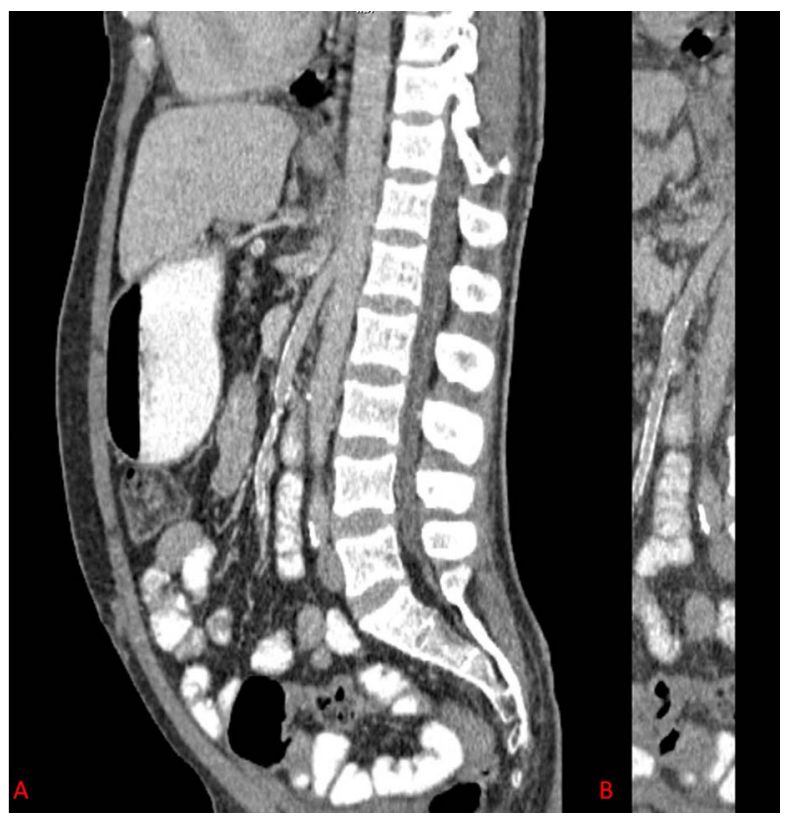

Figure 1 (A) Sagittal oblique reformatted CT image, (B) curved maximum intensity projection image demonstrating widespread atherosclerotic calcifications in superior mesenteric artery.

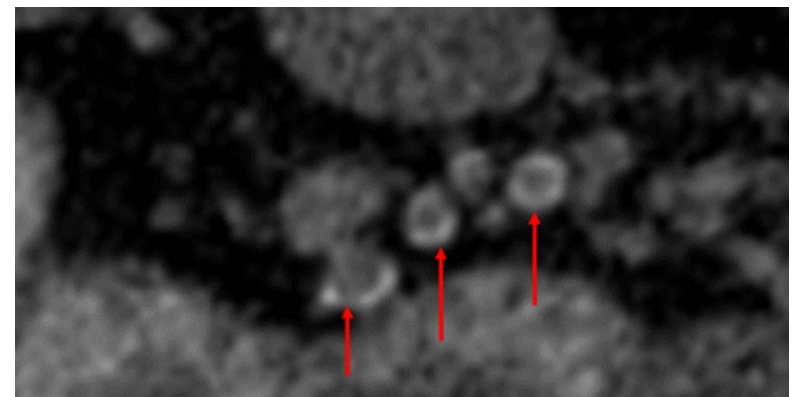

Figure 2 Panzoom image of axial CT (A and B) showing widespread atherosclerotic calcifications (arrows) in branches of superior mesenteric artery (ileal, ileocolic and right colic arteries).

anatomic sites, such as infrarenal abdominal aorta. ${ }^{2}$ However, origin of the SMA was spared in our patient while there was diffuse circumferential calcification in more distal parts of SMA and its individual branches.

CMI is the most frequent complication of SMA atherosclerosis and clinically presents with postprandial abdominal discomfort or intradialytic abdominal pain caused by hypotension. CMI can also present with atypical symptoms such as vomiting, diarrhoea, constipation and ischaemic colitis. ${ }^{3}$ However, in the case of thromboembolism or critical stenosis of artery lumen CMI may manifest as acute mesenteric ischaemia that it is associated with high mortality. ${ }^{1}$ Here, we report a patient who was free of symptoms but widespread calcifications in superior SMA in CT images. Interestingly the pattern of calcification was different in that ostium was spared while branches of the artery were severely inflicted. The patient had no apparent cardiovascular risk factor apart from being a diabetic haemodialysis patient. Even relatively younger haemodialysis patients suffer from widespread calcification. This is not always symptomatic and may present with sudden cardiac death in many patients. ${ }^{4}$ Endovascular therapy with stenting is the most common method of revascularisation in this patient. This figure illustrates the heavy burden of calcification in haemodialysis patients even when no apparent cardiovascular risk factors prevail. 


\section{BMJ Case Reports}

\section{Learning points}

- The vascular calcification is one of the most dreaded complications of long-term haemodialysis treatment.

- Relatively younger patient had asymptomatic isolated calcification of distal branches of SMA and he is at a high risk of acute mesenteric ischemia and sudden death.

- Endovascular therapy with stenting is the most common method of revascularisation in this patient.
Competing interests None.

Patient consent Obtained

\section{REFERENCES}

1. Li SY, Chen YT, Chen TJ, et al. Mesenteric ischemia in patients with end-stage renal disease: a nationwide longitudinal study. Am J Nephrol 2012;35:491-7.

2. Blacher J, Guerin AP, Pannier B, et al. Arterial calcifications, arterial stiffness, and cardiovascular risk in end-stage renal disease. Hypertension 2001;38:938-42.

3. White CJ. Chronic mesenteric ischemia: diagnosis and management. Prog Cardiovasc Dis 2011:54:36-40.

4. Green D, Roberts PR, New DI, et al. Sudden cardiac death in hemodialysis patients: an in-depth review. Am J Kidney Dis 2011;57:921-9.

Copyright 2012 BMJ Publishing Group. All rights reserved. For permission to reuse any of this content visit http://group.bmj.com/group/rights-licensing/permissions.

BMJ Case Report Fellows may re-use this article for personal use and teaching without any further permission.

Please cite this article as follows (you will need to access the article online to obtain the date of publication).

Ozbek O, Solak Y, Gaipov A, Turk S. Eccentric superior mesenteric artery calcification in a haemodialysis patient. BMJ Case Reports 2012;10.1136/bcr-2012-006397, Published XXX

Become a Fellow of BMJ Case Reports today and you can:

- Submit as many cases as you like

- Enjoy fast sympathetic peer review and rapid publication of accepted articles

- Access all the published articles

- Re-use any of the published material for personal use and teaching without further permission

For information on Institutional Fellowships contact consortiasales@bmjgroup.com

Visit casereports.bmj.com for more articles like this and to become a Fellow 